\title{
Anti-CD22 CAR-T Cell Therapy as a Salvage Treatment in B Cell Malignancies Refractory or Relapsed After Anti-CD 19 CAR-T therapy
}

\author{
Haibo Zhu (D) \\ Haobin Deng ${ }^{2}$ \\ Juan $M u^{\prime}$ \\ Cuicui Lyu' \\ Yanyu Jiang' \\ Qi Deng'
}

'Department of Hematology, Tianjin First Central Hospital, School of Medicine, Nankai University, Tianjin, People's Republic of China; ${ }^{2}$ The First Central Clinical College of Tianjin Medical University, Tianjin, People's Republic of China
Correspondence: Qi Deng

No. 24, Fukang Road, Tianjin, People's

Republic of China

$\mathrm{Tel}+86 / 36 / 2055872$

Email kachydeng@126.com
Background: To observe efficacy of the anti-CD22 chimeric antigen receptor modified (anti-CD22-CAR) $\mathrm{T}$ cell salvage therapy in relapsed/refractory $(\mathrm{R} / \mathrm{R})$ diffuse large B-cell lymphoma (DLBCL) and B cell acute lymphoid leukemia (B-ALL) patients whose disease did not reach CR or progressed again after anti-CD19-CAR T cell therapy.

Methods: In our study, seven R/R DLBCL patients reached stable disease (SD) or progression of disease (PD) after their anti-CD19-CAR T cell therapy. Only three in all the six R/R B-ALL patients obtained complete response (CR)/CR with incomplete count recovery (Cri) in their anti-CD19-CAR T cell therapy, but they relapsed again in the following three, six and one months. Then, all these thirteen R/R DLBCL and B-ALL patients received anti-CD22 CAR-T cell salvage therapy because their disease did not reach $C R$ or progressed again.

Results: Four R/R DLBCL patients obtained CR, while two R/R DLBCL patients achieved PR and one patient achieved SD. But only two R/R B-ALL patients obtained Cri in their anti-CD22 CAR-T cell salvage therapy. The overall survival (OS) of R/R DLBCL patients after the anti-CD22 CAR-T cell therapy was 6.142 \pm 3.395 months until August 31, 2020. There was no different of the median expansion peaks of the two kinds of CAR T cells $(P=0.920)$. The time of anti-CD22-CAR T cell proportion peak days was later than that of the time of anti-CD19-CAR $\mathrm{T}$ cell peak days post infusion $(P=0.022)$. Their cytokine release syndrome (CRS) was graded 2-4 in their anti-CD19-CAR T cell therapy, while the notable CRS was graded 1-2 in their anti-CD22-CAR T cell therapy. But there was no difference in the CRS and the immune effect or cell associated neurotoxic syndrome (ICANS) grades in the two kinds of therapies. And there was no difference in the hematological toxicity grades in the two kinds of therapies.

Conclusion: The anti-CD22-CAR T cell salvage therapy is highly effective in R/R DLBCL patients than in R/R B-ALL patients who failed in anti-CD19-CAR T cell therapy before. We need to expand the number of R/R DLBCL or B-ALL patients and continue to observe.

Trial Registration: ChiCTR-ONN-16009862 and ChiCTR1800019298.

Keywords: chimeric antigen receptor, CAR, diffuse large B-cell lymphoma, acute lymphoblastic leukemia, anti-CD19, anti-CD22

\section{Background}

Although many acute lymphoid leukemia (ALL) and Non-Hodgkin's lymphoma (NHL)patients could benefit from the conventional treatments of chemotherapy and hematopoietic stem cell transplantation, the relapsed/refractory $(R / R)$ of these disease leads to a very poor prognosis and high mortality. Anti-chimeric antigen receptor $(\mathrm{CAR}) \mathrm{T}$ cell therapy has been an effective salvage therapy for $\mathrm{R} / \mathrm{R}$ 
hematologic malignancy, especially the anti-CD19 CAR-T therapy in R/R B-cell ALL and B-cell NHL. ${ }^{1-4}$ Tisagenlecleucel as the first second-generation anti-CD19 CAR-T cell therapy has approved by FDA in 2017 in R/R B-cell ALL patients. ${ }^{5}$ Although the anti-CD19 CAR-T cell therapy has amazing curative effect in R/R B-cell hematologic malignancy, the disease recurrence or progresses again after this anti-CD19 CAR-T cell therapy is a serious problem which needs to be solved urgently. One of the reasons is that the CD19 target antigen might be lost or down regulated in these patients when their disease recurrence or progresses again. ${ }^{6-9}$ Similar to CD19, CD22 is also a B-cell antigen expressed specially on the surface of most B-cell malignancies. Anti-CD22 CAR-T cell therapy provides a potential treatment strategy in addition to antiCD19 CAR-T cell therapy. ${ }^{8,10,11}$ A study reported that anti-CD22 CAR-T cell therapy induced high response rates in R/R B-ALL patients whom had failed or relapsed again after a previous CD19 CAR-T cell therapy. ${ }^{12}$

\section{Patients and Methods}

\section{Medical History of the Patients Before Anti-CDI9-CAR T Cell Therapy}

Thirteen R/R diffuse large B-cell lymphoma (DLBCL) and B-ALL patients were admitted in our hospital between August 2017 and July 2018. Seven of them were R/R DLBCL patients, while six of them were R/R B-ALL patients. They all received the anti-CD19 CAR-T cell therapy when they were diagnosed as R/R DLBCL or R/RBALL. No patients received hematopoietic stem cell transplant(HSCT) before the two kinds of CAR-T cell therapy. The cutoff date of data collection is August 31, 2020.

\section{Detection of the Anti-CDI9-CAR-T and Anti-CD22-CAR-T Cell}

The culture time of anti-CD19 CAR-T cells and anti-CD22 CAR-T cells in vitro was approximately 12 to 14 days. Anti-CD19 CAR and anti-CD22 CAR transduction efficiencies were analyzed by flow cytometry (FCM) to observe the ratio of anti-CD19-CAR T cells and antiCD22-CAR $\mathrm{T}$ cells (PE, BD Biosciences) in $\mathrm{CD}^{+}$ $T$ cells (FITC, BD Biosciences).

\section{Clinical Response Criteria}

To R/R DLBCL patients, therapy responses were assessed one and two months post CAR-Tcell infusion. The response to this therapy was defined as complete response (CR), partial remission (PR), stable disease (SD) and progression of disease (PD) were defined according to Lugano Revised Criteria for Response Assessment. ${ }^{13}$ To R/R B-ALL patients, therapy responses were assessed 14 days post CAR-T cell infusion. The response to this therapy was defined as complete response (CR), CR with incomplete count recovery (Cri), or no remission (NR). In our study, we observed the overall survival (OS) and the progression-free survival (PFS) in all the patients. From the date of CAR-T cell infusion, follow-up was carried out up to the cutoff date or the date of death.

\section{The Anti-CDI9-CAR T Cell Therapy}

All the thirteenR/R DLBCL and B-ALL patients had received the clinical trial of anti-CD19 CAR-T cell expressing anti-CD19 scFv and 4-1BB-CD3 $\zeta$ costimulatoryactivation domains therapy (ChiCTR-ONN-16009862) in our hospital. The leukapheresis was done when they were enrolled in this anti-CD19-CAR $\mathrm{T}$ cell therapy clinical trial. Then the procedures for cell production and qualitycontrol assays were conducted according to our literature before. ${ }^{14}$ All the patients received lymphodepleting chemotherapy with fludarabine $\left(30 \mathrm{mg} / \mathrm{m}^{2}\right)$ and cyclophosphamide $\left(400 \mathrm{mg} / \mathrm{m}^{2}\right)$ from day -4 to day -2 . Autologous anti-CD19-CAR T cells were infused on day 0 in $\mathrm{R} / \mathrm{R}$ DLBCL and B-ALL patients $\left(2 \times 10^{6}\right.$ cells $\left./ \mathrm{kg}\right)$.

\section{The Anti-CD22-CAR T Cell Therapy}

All the patients whose disease did not reach CR or progressed again after anti-CD19-CAR T cell therapy received combination chemotherapy when they were waiting to enroll in the anti-CD22 CAR-T cell therapy. None of the patients received HSCT during this period. Then they received the anti-CD22 CAR-T cell therapy as a salvage therapy. It was a clinical trial of anti-CD22 chimeric antigen receptor (CAR) modified T-cell expressing anti-CD22 scFv and 4-1BB-CD3 $\zeta$ costimulatory-activation domains therapy (ChiCTR1800019298) in our hospital. The leukapheresis was done again when they were enrolled in the anti-CD22-CAR T cell therapy clinical trial. The procedures for cell production and quality-control assays were as same as the anti-CD19 CAR-T cell therapy. They received the same lymphodepleting chemotherapy as that in the anti-CD19 CAR-T cell therapy. Autologous antiCD22-CAR T cells were infused on day 0 in R/R DLBCL and B-ALL patients $\left(2 \times 10^{6}\right.$ cells $\left./ \mathrm{kg}\right)$. 


\section{The Proportions of Anti-CDI9-CAR}

T Cell and Anti-CD22-CAR T Cell, The

Expression of CAR 19 DNA and CAR

\section{DNAin Peripheral Blood}

In peripheral blood, the proportions of anti-CD19-CAR

$\mathrm{T}$ cells and anti-CD22-CAR T cells in CD3+ T cells was observed by flow cytometry (FCM) on day $0,4,7,14$, 21 and 28. The expression of CD19 CAR DNA and CD22 CAR DNA was detected by quantitative polymerase chain reaction (qPCR) method on day $0,4,7.14,21$ and 28 .

\section{Adverse Events (AEs) Observation in the Anti-CDI9-CAR T Cell and the Anti-CD22-CAR T Cell Therapy}

The levels of the interleukin-6 (IL-6), IL-2R, IL-8, and tumor necrosis factor- $\alpha$ (TNF- $\alpha$ ), were observed on, 4,7 , 14, 21, and 28 days after CAR-T cell infusion by enzymelinked immunosorbent assay. The AEs were observed throughout the two kinds of CAR-T cell therapy. The cytokine release syndrome (CRS) grade was determined according to the National Cancer Institute Common Terminology Criteria for $\mathrm{AE}$ v4.03. ${ }^{15}$ The neurotoxicity syndrome was determined according to the Immune effector cell associated neurotoxic syndrome (ICANS) ${ }^{16}$ in the two therapies.

\section{Statistical Analysis}

The differences between the anti-CD19-CAR T cell therapy and the anti-CD22-CAR T cell therapy were analyzed. Chi-square test was used for counting data. $T$ test was used for the measurement data conforming to normal distribution, and rank sum test was used for the measurement data not conforming to normal distribution. Nonnormal distribution data are expressed as a median and interquartile range (IQR) unless otherwise indicated. The probabilities of PFS and OS were estimated by the Kaplan-Meier method and were compared with the Log rank test. SPSS 17.0 (SPSS Inc., Chicago, IL, USA) software was used for all the statistical analyses in our study. The $P$-value less than 0.05 was considered statistically significant.

\section{Results}

\section{Patient Characteristics}

The patient characteristics of the thirteen R/R DLBCL and B-ALL patients before their anti-CD19-CAR T cell therapy are listed in Table 1. High CD19 antigen was expressed on

Table I Patients Baseline and Therapy-Related Characteristics

\begin{tabular}{|c|c|c|c|c|c|c|c|c|}
\hline $\begin{array}{l}\text { Patient } \\
\text { Number }\end{array}$ & Age & Sex & $\begin{array}{l}\text { Disease } \\
\text { Diagnosis }\end{array}$ & $\begin{array}{l}\text { Immune } \\
\text { Subtype }\end{array}$ & Stage & $\begin{array}{c}\text { Previous } \\
\text { Response Status }\end{array}$ & $\begin{array}{l}\text { IPI in DLBCL or } \\
\text { Blasts in B-ALL }\end{array}$ & $\begin{array}{c}\text { No. of Prior } \\
\text { Therapies }\end{array}$ \\
\hline PI & 56 & Male & DLBCL & Non-GCB & III & Refractory & 3 & 12 \\
\hline P2 & 16 & Male & DLBCL & Non-GCB & IV & Refractory & 3 & 8 \\
\hline P3 & 70 & Female & DLBCL & GCB & IV & Refractory & 4 & 8 \\
\hline P4 & 59 & Male & DLBCL & GCB & III & Refractory & 3 & 14 \\
\hline P5 & 28 & Male & DLBCL & Non-GCB & III & Refractory & 3 & 12 \\
\hline P6 & 56 & Female & DLBCL & Non-GCB & IV & Refractory & 3 & 7 \\
\hline P7 & 69 & Male & DLBCL & GCB & III & Refractory & 3 & 6 \\
\hline P8 & 46 & Male & B-ALL & Common B & - & Relapse & $81.2 \%$ & 4 \\
\hline P9 & 33 & Male & B-ALL & Common B & - & Relapse & $69.4 \%$ & 8 \\
\hline PIO & 25 & Male & B-ALL & Common $\mathrm{B}(\mathrm{Ph}+)$ & - & Refractory & $48.8 \%$ & 10 \\
\hline PII & 55 & Female & B-ALL & Common $\mathrm{B}(\mathrm{Ph}+)$ & - & Relapse & $36.2 \%$ & 6 \\
\hline $\mathrm{PI} 2$ & 31 & Female & B-ALL & Pro-B cell & - & Refractory & $44.6 \%$ & 3 \\
\hline $\mathrm{PI3}$ & 58 & Female & B-ALL & Common B & - & Relapse & $58.0 \%$ & 8 \\
\hline
\end{tabular}

Abbreviations: DLBCL, Diffuse large B-cell lymphoma; B-ALL, B cell acute lymphoid leukemia; GCB, Germinal center B-cell-like lymphoma; CR, Complete response; PR, Partial remission; SD, Stable disease; PD, progression of disease; NR, no remission; Cri, CR with incomplete count recovery. 

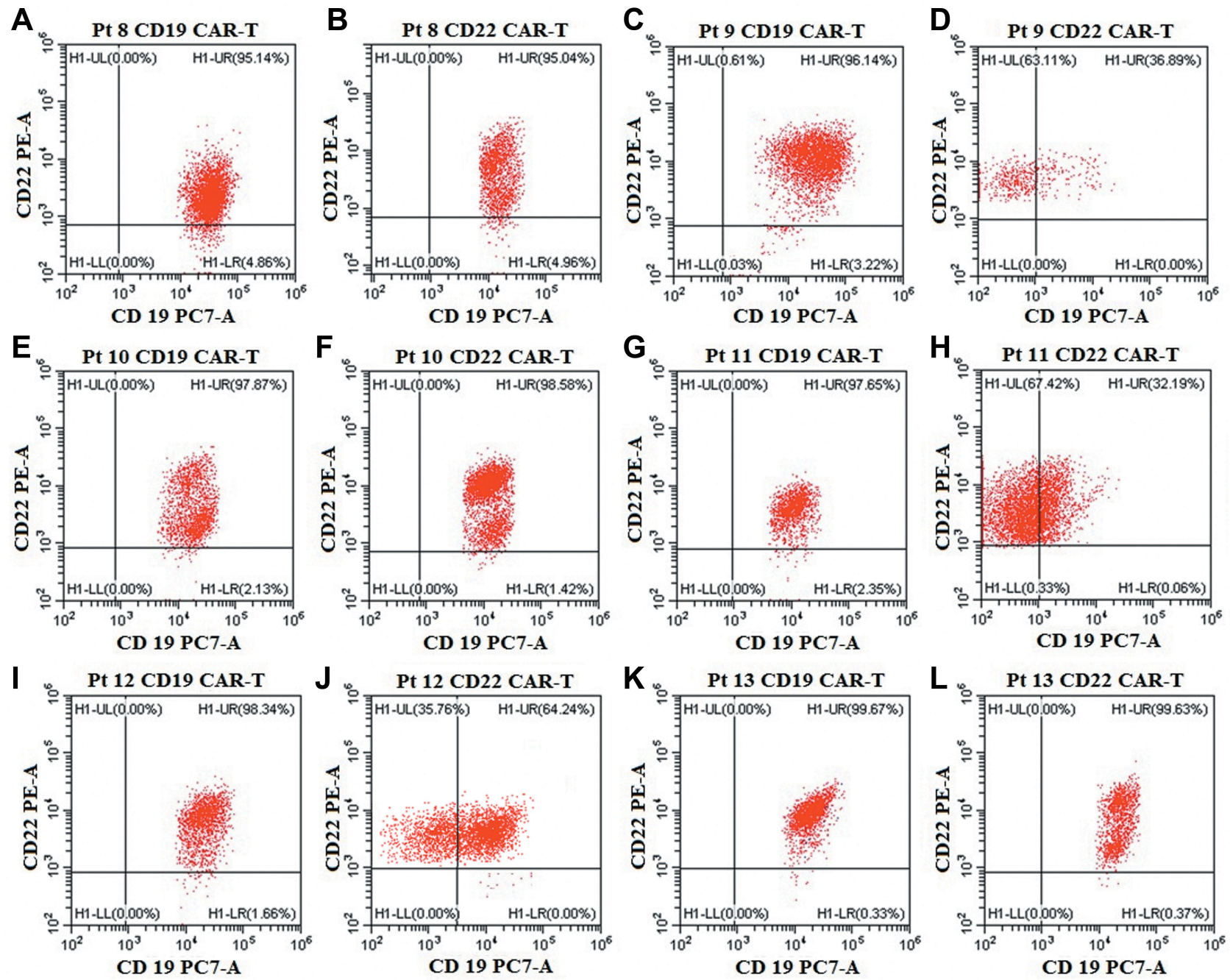

Figure I CDI9 and CD22 antigen expression on malignant B cells in the six R/R B-ALL patients. (A, C, E, G, I, K). High expression ofCDI9 antigen on malignant B cells in the six R/R B-ALL patients before anti-CDI9-CAR T cell therapy. (B, D, F, H, J, L). Normal or low expression of CDI 9 antigen, with high expression of CD22 antigen on malignant $B$ cells in the six R/R B-ALL patients before anti-CD22-CAR T cell therapy.

malignant $B$ cells analyzed by FCM in all the six $R / R$ B-ALL patients (Figure 1). All the thirteen R/R DLBCL and B-ALL patients received the anti-CD22 CAR-T cell therapy because their disease was diagnosed as nonremission or progress again after the previous anti-CD19 CAR-T cell therapy. The median age of all the patients was 46.31 years (Range 16-70 years) in our study.

\section{Transduction Efficiency, Amplification and} Infusion of the Two Kinds of CAR-T Cells The mean anti-CD19-CAR transduction efficiency of the thirteen patients was $47.18 \pm 17.43 \%$. The mean quantity of antiCD19-CAR T cells were $5.89 \pm 3.93 \times 10^{6}$ cells $/ \mathrm{kg}$ when the cells were harvested. Autologous anti-CD19-CAR T cells were infused on day 0 in $R / R$ DLBCL patients $(2.09$ $\pm 0.17 \times 10^{6}$ cells $\left./ \mathrm{kg}\right)$ and in $\mathrm{R} / \mathrm{R}$ B-ALL patients $(2.05$ $\pm 0.29 \times 10^{6}$ cells $\left./ \mathrm{kg}\right)$.

The mean CD22-CAR transduction efficiency in the final products of the thirteen patients was $42.07 \pm 19.23 \%$. The mean quantities of anti-CD22-CAR T cells were 4.03 $\pm 2.37 \times 10^{6}$ cells $/ \mathrm{kg}$. Autologous anti-CD22-CAR T cells were infused on day 0 in $\mathrm{R} / \mathrm{R}$ DLBCL patients $(2.11$ $\pm 0.24 \times 10^{6}$ cells $\left./ \mathrm{kg}\right)$ and in $\mathrm{R} / \mathrm{R}$ B-ALL patients $(2.07$ $\pm 0.42 \times 10^{6}$ cells $/ \mathrm{kg}$ ).

\section{Clinical Responses to Anti-CDI9-CAR T Cell Therapy}

One and two months post the anti-CD19-CAR T cell infusion, we evaluated the efficacy of all the seven $R / R$ DLBCL patients. Four R/R DLBCL patients (Pt 1-3, 5) 

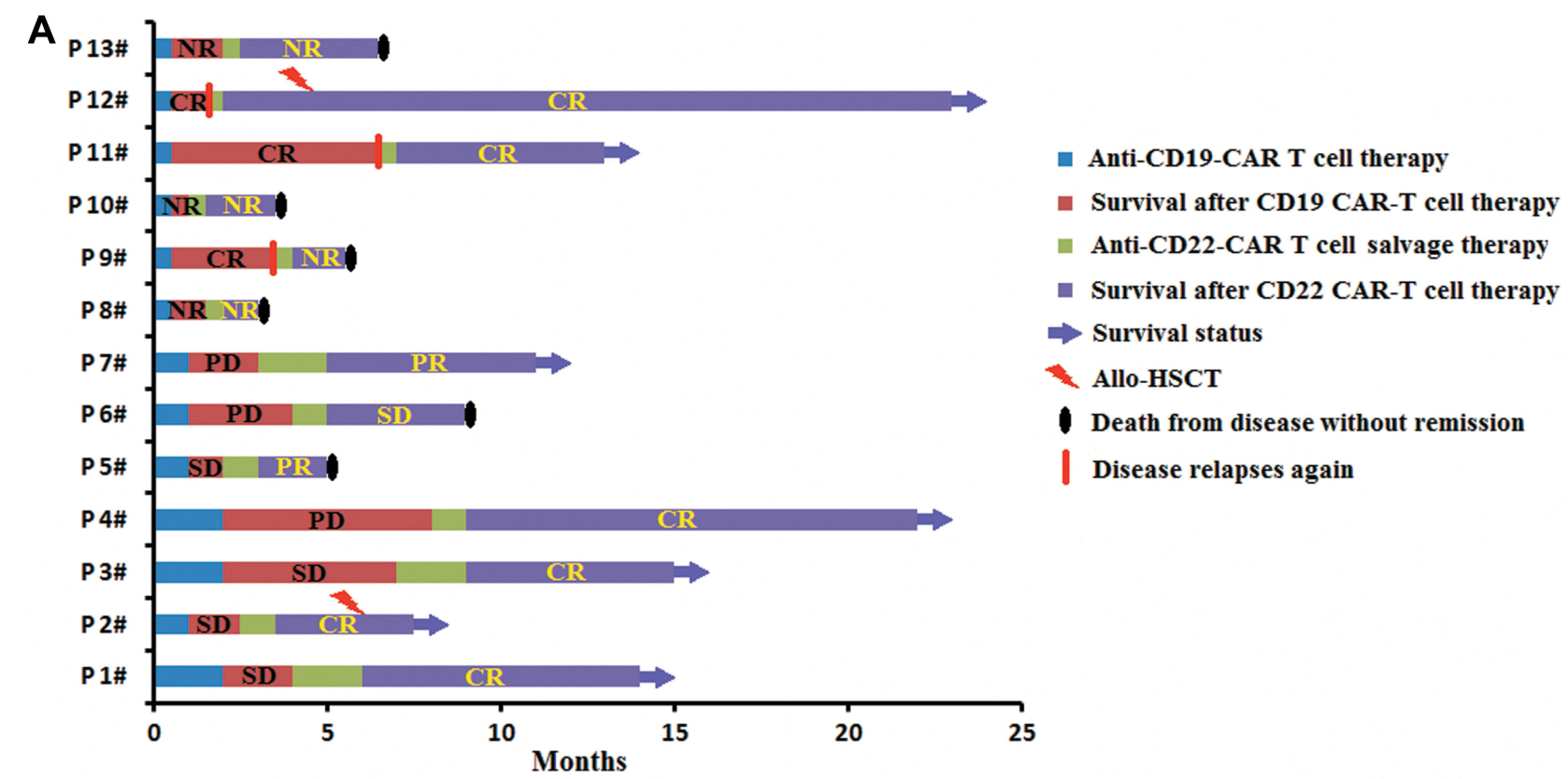

B DLBCL C

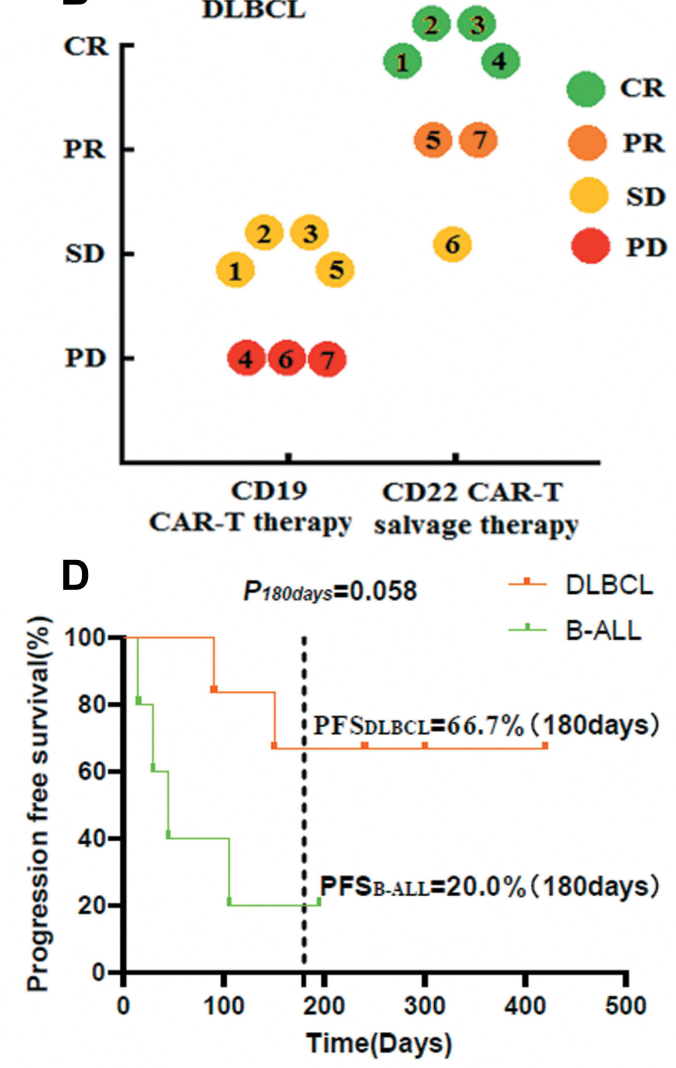

B-ALL
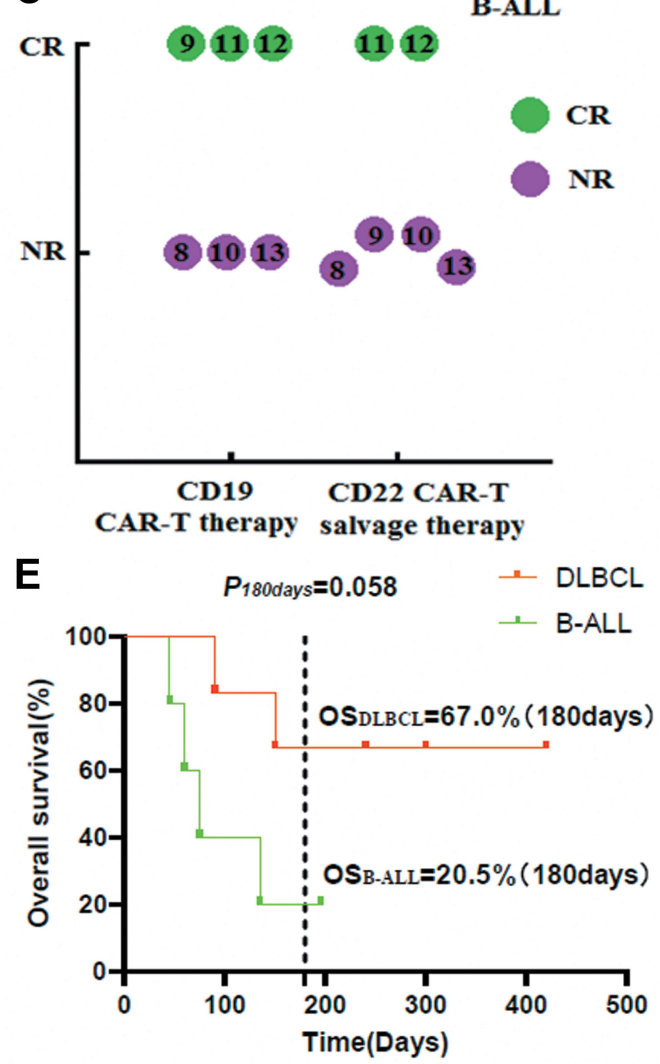

Figure 2 Clinical responses to the two kinds of CAR-T cell therapy. (A). Clinical responses and survival time of all the thirteen R/R DLBCL and B-ALL patients. (B). Clinical responses to the two kinds of CAR-T cell therapy in the seven R/R DLBCL patients. (C). Clinical responses to the two kinds of CAR-T cell therapy in the six R/R B-ALL patients. D. PFS and OS in the R/R DLBCL and B-ALL patients after their anti-CD22-CAR T cell therapy.

obtained SD from the anti-CD19-CAR $T$ cell therapy. Three R/R DLBCL patients (Pt 4, 6.7) did not respond to the anti-CD19-CAR T cell therapy and achieved PD only
(Figure 2A and B).The patient's disease did not allow a biopsy for immunohistochemical detection of CD22 expression before their anti-CD22-CAR T cell therapy. 
Two weeks post the anti-CD19-CAR T cell infusion, we evaluated the efficacy of the six R/R B-ALL patients. Three R/R B-ALL patients (Pt 9, 11, 12) obtained CR/Cri, while the other three R/R B-ALL patients (Pt 8, 10,13) obtained NR with high CD19 expression on malignant $\mathrm{B}$ cells. Although the three R/R B-ALL patients ( $\mathrm{Pt}$ 9, 11,12 ) achieved $C R / C r i$, they relapsed again in the following three, six and one month (Figure $2 \mathrm{~A}$ and $\mathrm{C}$ ). The six R/R B-ALL patients had normal or low expression of CD19 antigen, and high expression of CD22 antigen on malignant $\mathrm{B}$ cells analyzed by FCM before their antiCD22 CAR-T cell therapy (Figure 1).

\section{Clinical Responses To anti-CD22-CAR T Cell Therapy}

One and two months after their anti-CD22-CAR $\mathrm{T}$ cell therapy, four R/R DLBCL patients (Pt 1-4) obtained CR, while two R/R DLBCL patients (Pt 5, 7) achieved PR and one patient (Pt 6) achieved SD (Figure 2A and B). Two weeks after the anti-CD22-CAR T cell infusion, only two R/R B-ALL patients (Pt 11, 12) obtained Cri, while the other four R/R B-ALL patients (Pt 8-10, 13) obtained NR only (Figure $2 \mathrm{~A}$ and $\mathrm{C}$ ).After their anti-CD22-CAR $\mathrm{T}$ cell therapy, Pt 2 and Pt 12 received allogeneic HSCT.

The anti-CD22 CAR-T cell therapy in R/R DLBCL patients, four (4/7) patients achieved CR, six (6/7) patients achieved overall response rate (ORR). Kaplan-Meier analysis showed that the PFS of R/R DLBCL patients and R/R ALL patients who did not receive allo-HSCT after the anti-CD22 CAR-T cell therapy are $66.7 \%$ and $20.0 \% 180$ days after anti-CD22 CAR-T cell therapy until August 31, 2020 ( $P=0.058)$. While the OS of $\mathrm{R} / \mathrm{R}$ DLBCL patients and R/R ALL patients who did not receive allo-HSCT after the anti-CD22 CAR-T cell therapy are $67.07 \%$ and 20.5\% 180 days after anti-CD22 CAR-T cell therapy $(P=0.058)$ (Figure $2 \mathrm{D}$ and $\mathrm{E})$.

\section{The Proportions of Two Kinds of CAR-T Cells, The Levels of Two Kinds of CAR DNA in Peripheral Blood}

The proportions of anti-CD19-CAR T cells and the levels of CD19 CAR DNA were detected 0, 4, 7, 14, 21, 28 days post the anti-CD19-CAR T cell infusion. Median expansion peak of the anti-CD19-CAR T cells in $\mathrm{CD}^{+} \mathrm{T}$ cells in peripheral blood was $2.36 \%(2.06,5.24) \%$ on $7(7,7)$ days post infusion. While, median expansion peak of the anti-CD22-CAR $\mathrm{T}$ cells was $2.24 \%(2.04,9.28) \%$ on $14(7,14)$ days post infusion (Figure 3A and B). The levels of CD19 CAR DNA and CD22 CAR DNA showed the same variation trend. The median peak of CD19 CAR DNA was 1290 (900, 2636) copies/ $\mu \mathrm{g}$ on $7(7,7)$ days post the anti-CD19-CAR $\mathrm{T}$ cell infusion. While, the median peak of CD22 CAR DNA was $1240(960,2580)$ copies/ $\mu g$ on $14(14,14)$ days post the anti-CD22-CAR T cell infusion (Figure 3C and D).

There was no different of the median expansion peaks of the two kinds of CAR-T cells, and no different of the median peak copy of the two kinds of CAR DNA $(P=0.920$ and $P=0.880)$. The time of anti-CD22-CAR $\mathrm{T}$ cell proportion peak were later than that of the time of anti-CD19-CAR T cell peak post infusion $(P=0.022)$. The DNA level CAR gene showed the same trend $(P=0.001)$ (Figure 4).

\section{Adverse Effects}

In the anti-CD19-CAR T cell therapy, patients developed fever with or without chills, fatigue, headache, nausea, edema, tachycardia, cough, and other symptoms (Table 2).The rates of CRS and ICANS were listed in Table 2. Their CRS was graded 2-4 in their anti-CD19CAR T cell therapy. The notable CRS was graded 1-2in their anti-CD22-CAR $T$ cell therapy. But there was no different of the CRS grades in the two kinds of therapy $(P=0.341)$ (Figure 5A). Two patients developed grade 1 ICANS in the anti-CD19-CAR $\mathrm{T}$ cell therapy. But no patient was diagnosed as ICANS in the anti-CD22-CAR T cell therapy. There was no different of the ICANS grades in the two kinds of therapy $(P=0.480)$ (Figure 5B). Hematological toxicity was grade $2-4$ in anti-CD19-CAR T cell therapy. While it was grade $1-3$ in their anti-CD22CAR T cell therapy. There was no different of the hematological toxicity grades in the two kinds of therapies $\left(P_{W B C}=0.148, P_{H b}=0.425\right.$ and $P_{P L T}=0.813$ ) (Figure 5CE). It occurred from 5 to 7 days after CAR-T cell infusion and recovered 14-16 days after the CAR-T cell infusion. Although the hematological toxicity in the process of therapy, only three R/R B-ALL patients were diagnosed with gram-negative organism bacterial infections in antiCD19-CAR T cell therapy. Their infectious disease was cured by antibiotics and supportive treatment. There was no patient was diagnosed with bacterial infections in $\mathrm{R} / \mathrm{R}$ DLBCL patients in their anti-CD19-CAR $T$ cell therapy, while no patient in all the thirteen patients was diagnosed with bacterial infections in anti-CD22-CAR T cell therapy. There was no patient was diagnosed with invasive fungal disease also. 

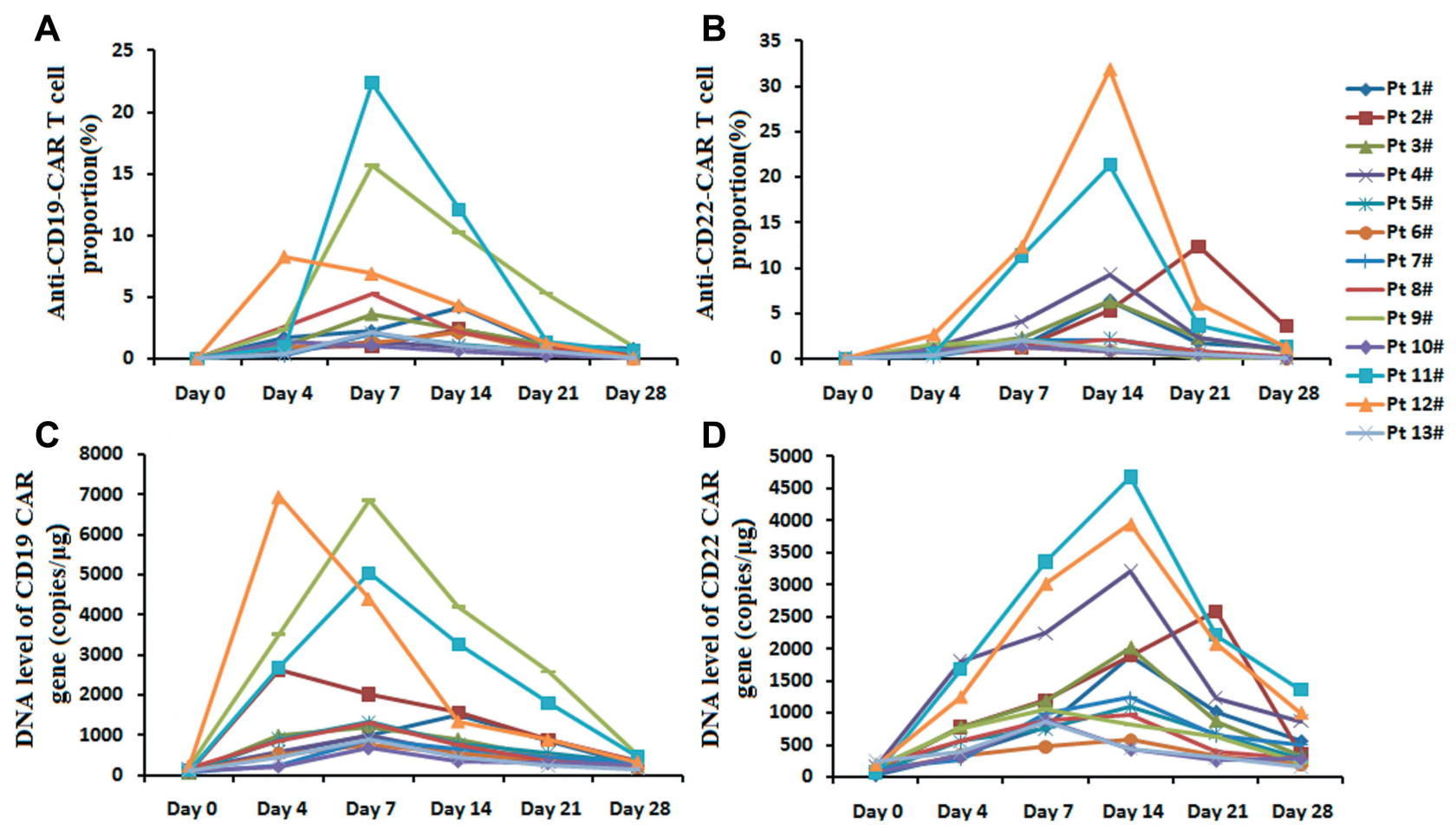

Figure 3 The proportions of two kinds of CAR-T cells, the levels of two kinds of CAR DNA in peripheral blood. (A and B). The proportions of two kinds of CAR-T cells on $0,4,7,14,21,28$ days post the CAR-T cell infusion. (C and D). The levels of two kinds of CAR DNA on 0, 4, 7, I4, 21,28 days post the CAR-T cell infusion.

\section{Serum Cytokines in anti-CDI9-CAR T Cell and Anti-CD22-CAR T Cell \\ Therapy}

The serum levels ofIL-6, IL-2R, IL- 8 and TNF- $\alpha$ were observed in the two kinds of CAR-T cell therapies (Figure $6 \mathrm{~A}-\mathrm{H}$ ). The peaks of IL-6, IL-2Rand TNF- $\alpha$ were higher in their anti-CD19-CAR T cell therapy than that of in their anti-CD22-CAR T cell therapy $\left(P_{I L-\sigma}=0.044, P_{I L-2 R}\right.$ $=0.004, P_{I L-8}=0.064$ and $P_{T N F-\alpha}=0.019$ )(Figure 7A-D). The mean peaks of IL-6, IL-8, IL-2R and TNF- $\alpha$ in anti-CD19CAR T cell therapy was at $6.61 \pm 2.53$ days, $5.15 \pm 1.46$ days, $6.61 \pm 2.53$ days and $6.85 \pm 2.41$ days after infusion. While the mean peaks of IL-6, IL-2R, IL-8 and TNF- $\alpha$ in anti-CD22CAR T cell therapy was at $11.08 \pm 3.93$ days, $11.85 \pm 3.36$ days, $12.38 \pm 3.07$ days and $11.31 \pm 3.54$ days after infusion. The time of the mean peaks of IL-6, IL-2R and TNF- $\alpha$ in anti-CD22-CAR $\mathrm{T}$ cell therapy were later than that of the time in anti-CD19-CAR T cell therapy $\left(P_{I L-\sigma}=0.005, P_{I L-2 R}\right.$ $=0.000, P_{I L-8}=0.239$ and $\left.P_{T N F-\alpha}=0.004\right) \quad$ (Figure 7E-H).

The patients received methylprednisolone, antipyretic drugs and symptomatic treatment to overcome the AEs. Only the R/R B-ALL patient 12 received tocilizumab during her anti-CD19-CAR T cell therapy and anti-CD22-
CAR T cell therapy. AEs related to the two kinds of CAR$\mathrm{T}$ cell therapies were relieved 14 to 16 days post the two kinds ofCAR-T cell infusion. No patients died of CRS and ICANS in their anti-CD19-CAR T cell oranti-CD22-CAR $\mathrm{T}$ cell therapy.

\section{Discussion}

Patients with $\mathrm{R} / \mathrm{R}$ B cell malignancies respond poorly to conventional treatment, anti-CD19-CAR T cell therapy had demonstrated remarkable anti-tumor activity for these patients and improved their prognosis. The CR rate of $\mathrm{R} / \mathrm{R}$ B-ALL to anti-CD19-CAR $\mathrm{T}$ cell therapy could be achieved about $70 \%$ to $90 \%,{ }^{17}$ while the overall response rate (ORR) of R/R B-NHL to anti-CD19-CAR T cell therapy could be achieved about $50 \%$ to $70 \% .{ }^{18-21}$ Despite the great success of anti-CD19-CAR T cell therapy in R/R B-ALL and B-NHL, there are still some patients with poor efficacy to this therapy. ${ }^{6,22,23}$ Patients relapsed after anti-CD19-CAR $T$ cell therapy with lost or mutated of CD19 expression on tumor cells, which was one of the reasons for the failure of the second anti-CD19-CAR T cell therapy. So we need other targets for CAR-T cell therapy as a salvage therapy to such patients. 

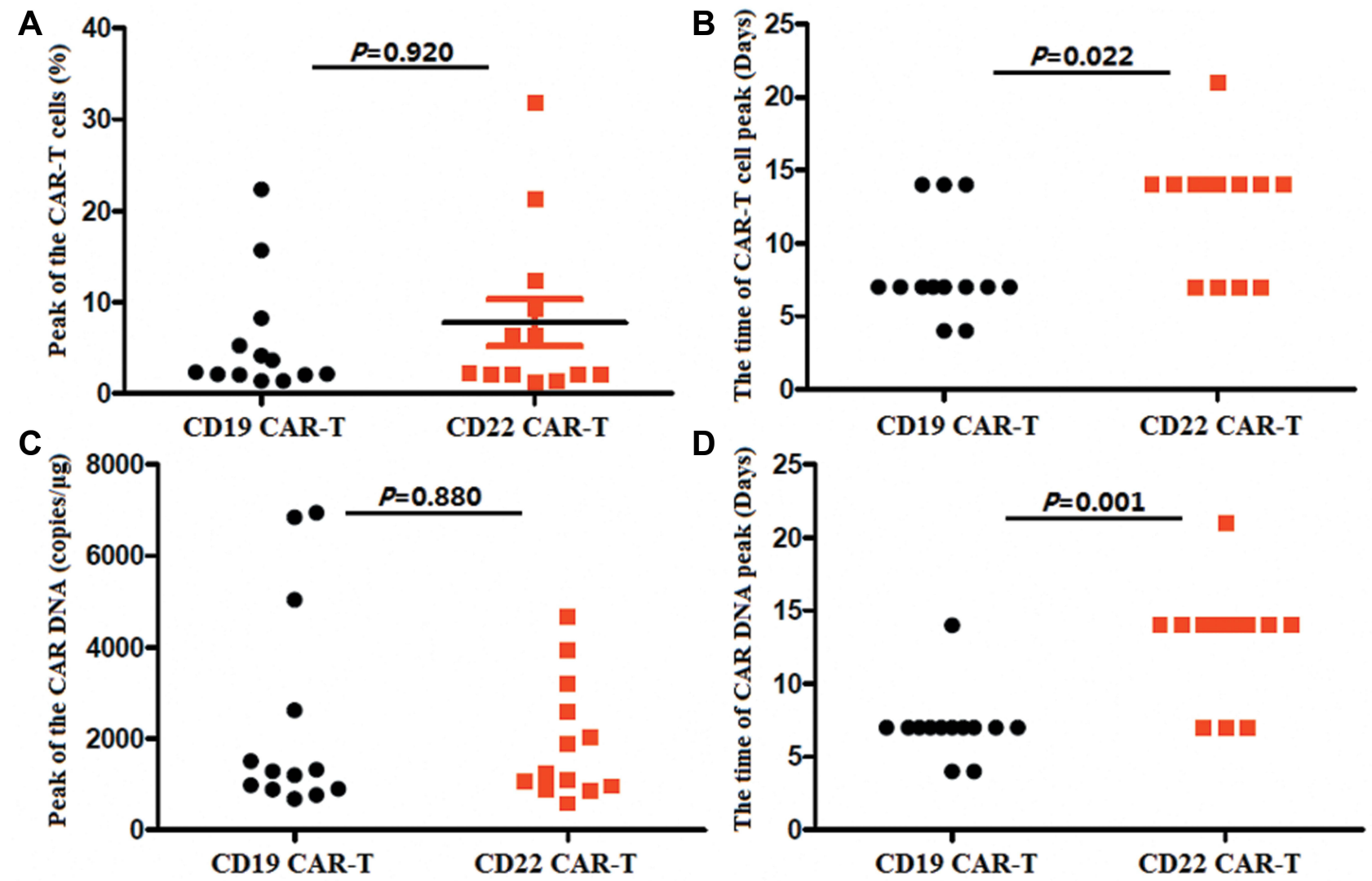

Figure 4 Different of the expansion of the two kinds of CAR-T cells. (A) There was no different of the median expansion peaks of the two kinds of CAR-T cells ( $P=0.920$ ). (B). The time of anti-CD22-CAR T cell proportion peak were later than that of the time of anti-CDI9-CAR T cell peak ( $P=0.022)$. (C). There was no different of the median peak of the two kinds of CAR DNA $(P=0.880)$. (D). The time ofCD22 CAR DNA peak were later than that of the time of CDI9 CAR DNA peak $(P=0.001)$.

CD22 as a type I transmembrane glycoprotein which expressed on the surface of tumor cells in most B cell malignancies, such as B-ALL, DLBCL, chronic lymphocytic leukemia, and other B-NHL. CD22 could be used as an ideal target for patients who relapse again after anti-CD19-CAR T cell therapy or has no response to anti-CD19-CAR T cell therapy. ${ }^{8,24-27}$ In previous studies, CD22 monoclonal antibodies, including epituzumab and Inotuzumab Ozogamicin, have been reported to have significant antitumor activity in patients with B-ALL or B-NHL. ${ }^{26,28-30}$ What about the efficacy of anti-CD22-CAR $\mathrm{T}$ cell therapy in patients with $\mathrm{B}$ cell malignancies that resist to anti-CD19-CAR $\mathrm{T}$ cell therapy? What is the efficacy of anti-CD22-CAR $\mathrm{T}$ cell therapy in patients with $\mathrm{R} / \mathrm{R}$ B-cell malignancies who relapse again after antiCD19-CAR T cell therapy or has no response to this therapy. A recent study reported that anti-CD22-CAR $\mathrm{T}$ cell therapy induced $\mathrm{CR}$ in $73 \%$ of $\mathrm{R} / \mathrm{R} \mathrm{B}-\mathrm{ALL}$ patients who were resistant or ineffective to anti-CD19CAR T cell therapy before. ${ }^{12}$ What is the efficacy of antiCD22-CAR T cell therapy in salvage therapy after failure of anti-CD19-CAR T cell therapy for R/R DLBCL? Future studies are needed to determine.

In our study, thirteen R/R DLBCL and B-ALL patients received anti-CD22 CAR-T cell salvage therapy when they relapsed after their previous anti-CD19 CAR-T cell therapy. Seven R/R DLBCL patients and six R/R B-ALL patients received the anti-CD19 CAR-T cell therapy. But the R/R DLBCL patients obtained SD or PD only, while three R/R B-ALL patients obtained NR, three R/R B-ALL patients relapsed again soon with low expression of CD19 on malignant $\mathrm{B}$ cells after they obtained CR/Cri. As a salvage treatment after this anti-CD19-CAR T cell therapy, they all received an anti-CD22 CAR-T cell therapy. Interestingly, except for one $\mathrm{R} / \mathrm{R}$ DLBCL patient who attained $\mathrm{SD}$, all the other six $\mathrm{R} / \mathrm{R}$ DLBCL patients received $\mathrm{CR}$ in the anti-CD22 CAR-T cell therapy. Only two R/R B-ALL patients obtained $\mathrm{CR} / \mathrm{Cri}$ in the antiCD22 CAR-T cell salvage therapy, although they all had high expression of CD22 on their malignant B cells. The PFS and OS of anti-CD22-CAR T cell salvage therapy were higher in $R / R$ DLBCL patients than that of in $R / R$ 
Table 2 The Notable Adverse Events (AEs) in the Two Time of CAR-T Cell Therapies

\begin{tabular}{|c|c|c|c|c|}
\hline \multirow[t]{2}{*}{ Events } & \multicolumn{2}{|c|}{ CDI9 CAR-T Therapy } & \multicolumn{2}{|c|}{ CD22 CAR-T Therapy } \\
\hline & DLBCL & $A L L$ & DLBCL & $A L L$ \\
\hline \multicolumn{5}{|l|}{ General condition } \\
\hline Temperature $\geq 38^{\circ} \mathrm{C}$ (fever) & $7 / 7(100 \%)$ & $6 / 6(100 \%)$ & I/7 (I4.29\%) & $4 / 6(66.67 \%)$ \\
\hline Chills & $2 / 7(28.57 \%)$ & $4 / 6(66.67 \%)$ & $0 / 7(0 \%)$ & $1 / 6(16.67 \%)$ \\
\hline Fatigue & $4 / 7(57.14 \%)$ & $5 / 6(83.33 \%)$ & $3 / 7(42.86 \%)$ & $4 / 6(66.67 \%)$ \\
\hline Headache & $0 / 7(0 \%)$ & $3 / 6(50 \%)$ & $0 / 7(0 \%)$ & $0 / 6(0 \%)$ \\
\hline Muscular weakness & I/7 (I4.29\%) & $4 / 6(66.67 \%)$ & $0 / 7(0 \%)$ & $1 / 6(16.67 \%)$ \\
\hline \multicolumn{5}{|l|}{ Organ toxicities } \\
\hline \multicolumn{5}{|l|}{ Hematological } \\
\hline Neutropenia (grade $3 / 4)\left(<1^{*} 10^{\wedge} 9 / L\right)$ & $3 / 7(42.86 \%)$ & $6 / 6(100 \%)$ & $\mathrm{I} / 7$ (14.29\%) & $2 / 6(33.33 \%)$ \\
\hline Anemia (grade $3 / 4)(<80 g / L)$ & $2 / 7(28.57 \%)$ & $5 / 6(83.33 \%)$ & $\mathrm{I} / 7$ (14.29\%) & $3 / 6(50 \%)$ \\
\hline Thrombocytopenia (grade 3/4) $\left(<50^{*} 10^{\wedge} 9 / \mathrm{L}\right)$ & $2 / 7(28.57 \%)$ & $6 / 6(100 \%)$ & $\mathrm{I} / 7$ (I4.29\%) & $5 / 6(83.33 \%)$ \\
\hline \multicolumn{5}{|l|}{ Respiratory } \\
\hline Hypoxia $(\mathrm{SaO} 2<90 \%)$ & I/7 (14.29\%) & $2 / 6(33.33 \%)$ & $0 / 7(0 \%)$ & $0 / 6(0 \%)$ \\
\hline Dyspnoea & $0 / 7(0 \%)$ & $4 / 6(66.67 \%)$ & $0 / 7(0 \%)$ & $0 / 6(0 \%)$ \\
\hline Cough & $2 / 7(28.57 \%)$ & $3 / 6(50 \%)$ & $0 / 7(0 \%)$ & $1 / 6(16.67 \%)$ \\
\hline Pleural effusion & $2 / 7(28.57 \%)$ & $3 / 6(50 \%)$ & $0 / 7(0 \%)$ & $2 / 6(33.33 \%)$ \\
\hline \multicolumn{5}{|l|}{ Gastrointestinal } \\
\hline Nausea & $3 / 7(42.86 \%)$ & $4 / 6(66.67 \%)$ & I/7 (14.29\%) & $1 / 6(16.67 \%)$ \\
\hline Vomiting & I/7 (I4.29\%) & $2 / 6(33.33 \%)$ & $0 / 7(0 \%)$ & $0 / 6(0 \%)$ \\
\hline Decreased appetite & I/7 (I4.29\%) & $3 / 6(50 \%)$ & $0 / 7(0 \%)$ & $1 / 6(16.67 \%)$ \\
\hline \multicolumn{5}{|l|}{ Hepatic } \\
\hline Increased serum ALT, AST & $2 / 7(28.57 \%)$ & $4 / 6(66.67 \%)$ & I/7 (14.29\%) & $2 / 6(33.33 \%)$ \\
\hline Increased serum bilirubin levels & I/7 (I4.29\%) & $2 / 6(33.33 \%)$ & $0 / 7(0 \%)$ & $0 / 6(0 \%)$ \\
\hline \multicolumn{5}{|l|}{ Renal } \\
\hline Increased serum creatinine levels & $0 / 7(0 \%)$ & $3 / 6(50 \%)$ & $0 / 7(0 \%)$ & $1 / 6(16.67 \%)$ \\
\hline Oliguria & $2 / 7(28.57 \%)$ & $3 / 6(50 \%)$ & $\mathrm{I} / 7$ (I4.29\%) & $1 / 6(16.67 \%)$ \\
\hline \multicolumn{5}{|l|}{ Heart } \\
\hline Tachycardia & $2 / 7(28.57 \%)$ & $4 / 6(66.67 \%)$ & $0 / 7(0 \%)$ & $2 / 6(33.33 \%)$ \\
\hline Arrhythmia & $0 / 7(0 \%)$ & $3 / 6(50 \%)$ & $0 / 7(0 \%)$ & $0 / 6(0 \%)$ \\
\hline Systolic blood pressure $<90 \mathrm{~mm} \mathrm{Hg}$ & $0 / 7(0 \%)$ & $2 / 6(33.33 \%)$ & $0 / 7(0 \%)$ & $0 / 6(0 \%)$ \\
\hline \multicolumn{5}{|l|}{ Coagulopathy } \\
\hline Disseminated intravascular coagulation & $0 / 7(0 \%)$ & $1 / 6(16.67 \%)$ & $0 / 7(0 \%)$ & $0 / 6(0 \%)$ \\
\hline \multicolumn{5}{|l|}{ Neurological } \\
\hline Encephalopathy & $0 / 7(0 \%)$ & $0 / 6(0 \%)$ & $0 / 7(0 \%)$ & $0 / 6(0 \%)$ \\
\hline Confused state & $0 / 7(0 \%)$ & $0 / 6(0 \%)$ & $0 / 7(0 \%)$ & $0 / 6(0 \%)$ \\
\hline Dizziness & $0 / 7(0 \%)$ & $4 / 6(66.67 \%)$ & $0 / 7(0 \%)$ & $1 / 6(16.67 \%)$ \\
\hline Aphasia & $0 / 7(0 \%)$ & $0 / 6(0 \%)$ & $0 / 7(0 \%)$ & $0 / 6(0 \%)$ \\
\hline Somnolence & I/7 (I4.29\%) & $3 / 6(50 \%)$ & $0 / 7(0 \%)$ & $2 / 6(33.33 \%)$ \\
\hline \multicolumn{5}{|l|}{ Cytokine release syndrome (CRS) } \\
\hline Grade 0 CRS & $5 / 7(71.43 \%)$ & $0 / 6(0 \%)$ & $4 / 7(57.14 \%)$ & $0 / 6(0 \%)$ \\
\hline Grade I CRS & I/7 (14.29\%) & $0 / 6(0 \%)$ & $2 / 7(28.57 \%)$ & $3 / 6(50 \%)$ \\
\hline Grade 2 CRS & I/7 (14.29\%) & $2 / 6(33.33 \%)$ & $\mathrm{I} / 7$ (14.29\%) & $2 / 6(33.33 \%)$ \\
\hline Grade 3 CRS & $0 / 7(0 \%)$ & $2 / 6(33.33 \%)$ & $0 / 7(0 \%)$ & $1 / 6(16.67 \%)$ \\
\hline Grade 4 CRS & $0 / 7(0 \%)$ & $2 / 6(33.33 \%)$ & $0 / 7(0 \%)$ & $0 / 6(0 \%)$ \\
\hline Grade 5 CRS & $0 / 7(0 \%)$ & $0 / 6(0 \%)$ & $0 / 7(0 \%)$ & $0 / 6(0 \%)$ \\
\hline \multicolumn{5}{|c|}{ Immune effector cell associated neurotoxic syndrome (ICANS) } \\
\hline Grade I ICANS & $0 / 7(0 \%)$ & $1 / 6(16.67 \%)$ & $0 / 7(0 \%)$ & $0 / 6(0 \%)$ \\
\hline Grade 2 ICANS & $0 / 7(0 \%)$ & $1 / 6(16.67 \%)$ & $0 / 7(0 \%)$ & $0 / 6(0 \%)$ \\
\hline
\end{tabular}

(Continued) 
Table 2 (Continued).

\begin{tabular}{|c|c|c|c|c|}
\hline \multirow[t]{2}{*}{ Events } & \multicolumn{2}{|c|}{ CDI9 CAR-T Therapy } & \multicolumn{2}{|c|}{ CD22 CAR-T Therapy } \\
\hline & DLBCL & $A L L$ & DLBCL & $A L L$ \\
\hline Grade 3 ICANS & $0 / 7(0 \%)$ & $0 / 6(0 \%)$ & $0 / 7(0 \%)$ & $0 / 6(0 \%)$ \\
\hline Grade 4 ICANS & $0 / 7(0 \%)$ & $0 / 6(0 \%)$ & $0 / 7(0 \%)$ & $0 / 6(0 \%)$ \\
\hline Grade 5 ICANS & $0 / 7(0 \%)$ & $0 / 6(0 \%)$ & $0 / 7(0 \%)$ & $0 / 6(0 \%)$ \\
\hline
\end{tabular}

B-ALL patients, but there was no difference in the $R / R$ DLBCL and R/R B-ALL patients.

The CRS and ICANS as the significant side effects were treatment-related toxicities of CAR-T cell therapies, which could be fatal if it was severe or not handled properly. ${ }^{1,17} \mathrm{In}$ our study, anti-CD22-CAR T cell therapy was more effective than anti-CD19-CAR T cell therapy in more patients. But the CRS was 1-2 grades in anti-CD22-CAR $\mathrm{T}$ cell therapy, while the CRS was 2-4 grades in anti-CD19CAR T cell therapy. There was no ICANS occurred in the anti-CD22-CAR T cell therapy, but it occurred in the antiCD19-CAR T cell therapy in two patients. It was consistent with previous studies. ${ }^{12,19,31,32}$ Hematological toxicity was more significant in anti-CD19-CAR T cell therapy than that of in anti-CD22-CAR $\mathrm{T}$ cell therapy. The anti-CD22-CAR $\mathrm{T}$ cell therapy showed effective anti-tumor activity as a salvage therapy with controllable toxicity. Another aspect is whether it could be used as an option for high-risk patients with ICANS in CAR- $\mathrm{T}$ cell therapies to $\mathrm{R} / \mathrm{R}$ B-ALL patients. The number of cases in this study is relatively small, we need to expand the number of $\mathrm{R} / \mathrm{R}$ DLBCL or B-ALL patients and continue to observe.

The cause of relapse again after the anti-CD22-CAR $T$ cell therapy is unknown at present. A study reported that R/R B-ALL patients who were poor efficacy to anti-CD19CAR T cell therapy might relapse again after their anti-CD22CAR T cell therapy. ${ }^{6}$ Another study demonstrated that the anti-CD22-CAR $T$ cell therapy is highly effective in $R / R$ B-ALL patients who had received prior anti-CD19-CAR T cell therapy might still face a high rate of recurrence. ${ }^{12}$ In our study, the anti-CD22-CAR T cell salvage therapy was not effective in such R/R B-ALLpatients. But we found that the

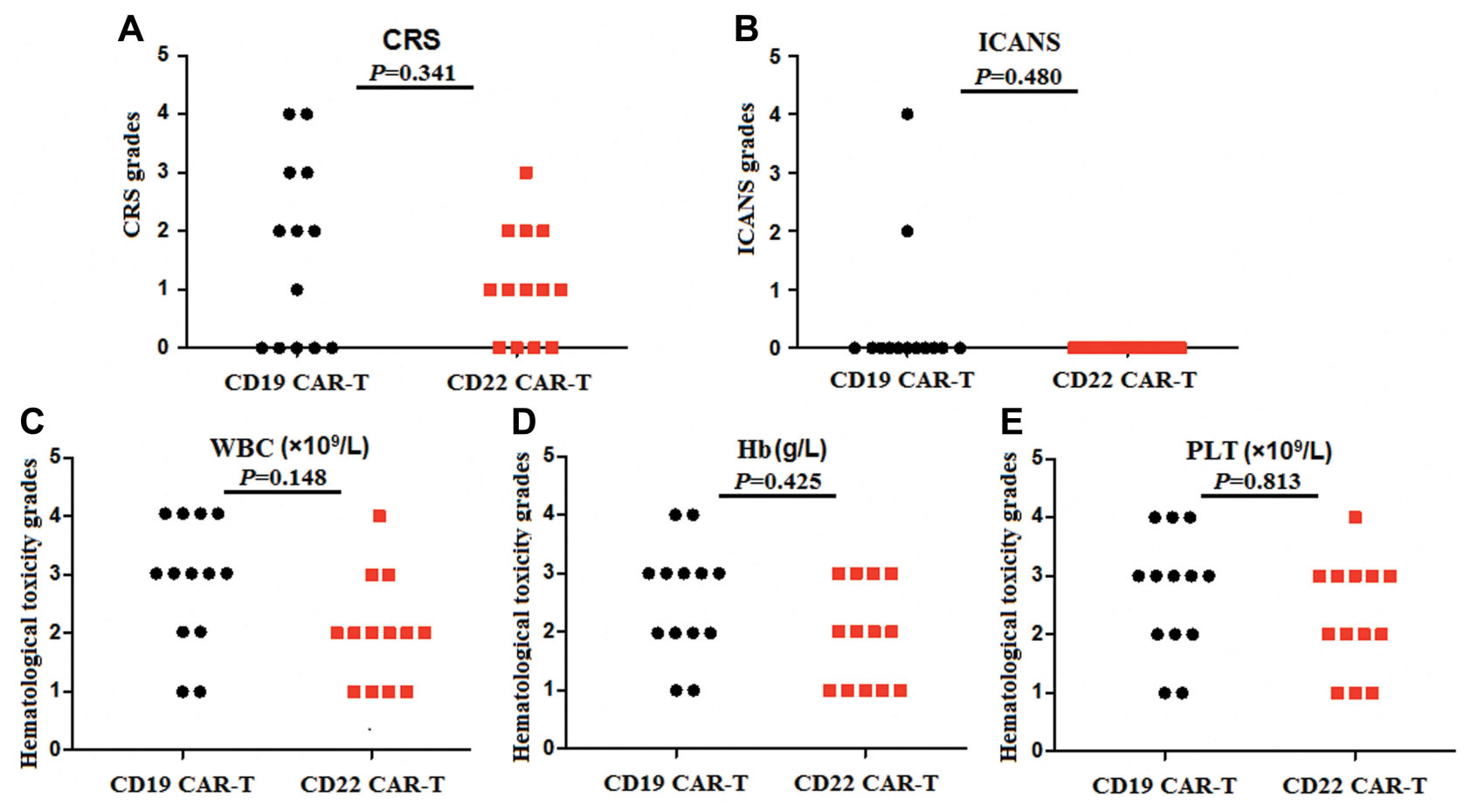

Figure 5 Grades of CRS, ICANS and hematological toxicity in the two kinds of CAR-T cell therapy. (A). There was no different of the CRS grades in the two kinds of therapy. (B). There was no different of the ICANS grades in the two kinds of therapy. (C-E). There was no different of the hematological toxicity grades in the two kinds of therapies. 

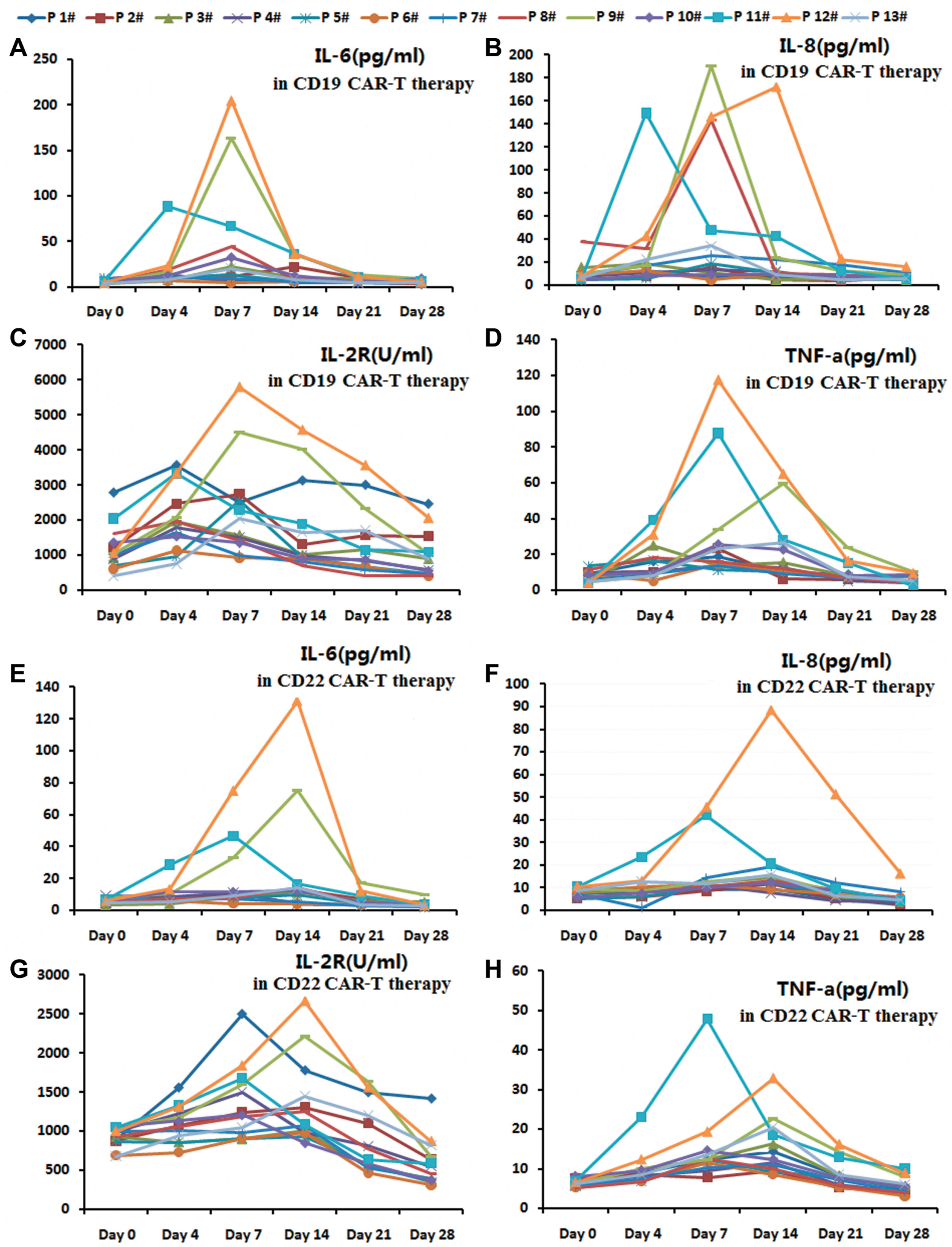

Figure 6 The serum levels of IL-6, IL-2R, IL-8 and TNF- $\alpha$ in anti-CDI9-CAR T cell and anti-CD22-CAR T cell therapy. (A). The serum levels of IL-6 in anti-CDI9-CAR T cell therapy. (B). The serum levels of IL-8 in anti-CDI9-CAR T cell therapy. (C). The serum levels of IL-2R in anti-CDI9-CAR T cell therapy. (D). The serum levels of TNF- $\alpha$ in anti-CDI9-CAR T cell therapy. (E). The serum levels of IL-6 in anti-CD22-CAR T cell therapy. (F). The serum levels of IL-8 in anti-CD22-CAR T cell therapy. (G). The serum levels of IL-2R in anti-CD22-CAR T cell therapy. (H). The serum levels of TNF- $\alpha$ in anti-CD22-CAR T cell therapy. 

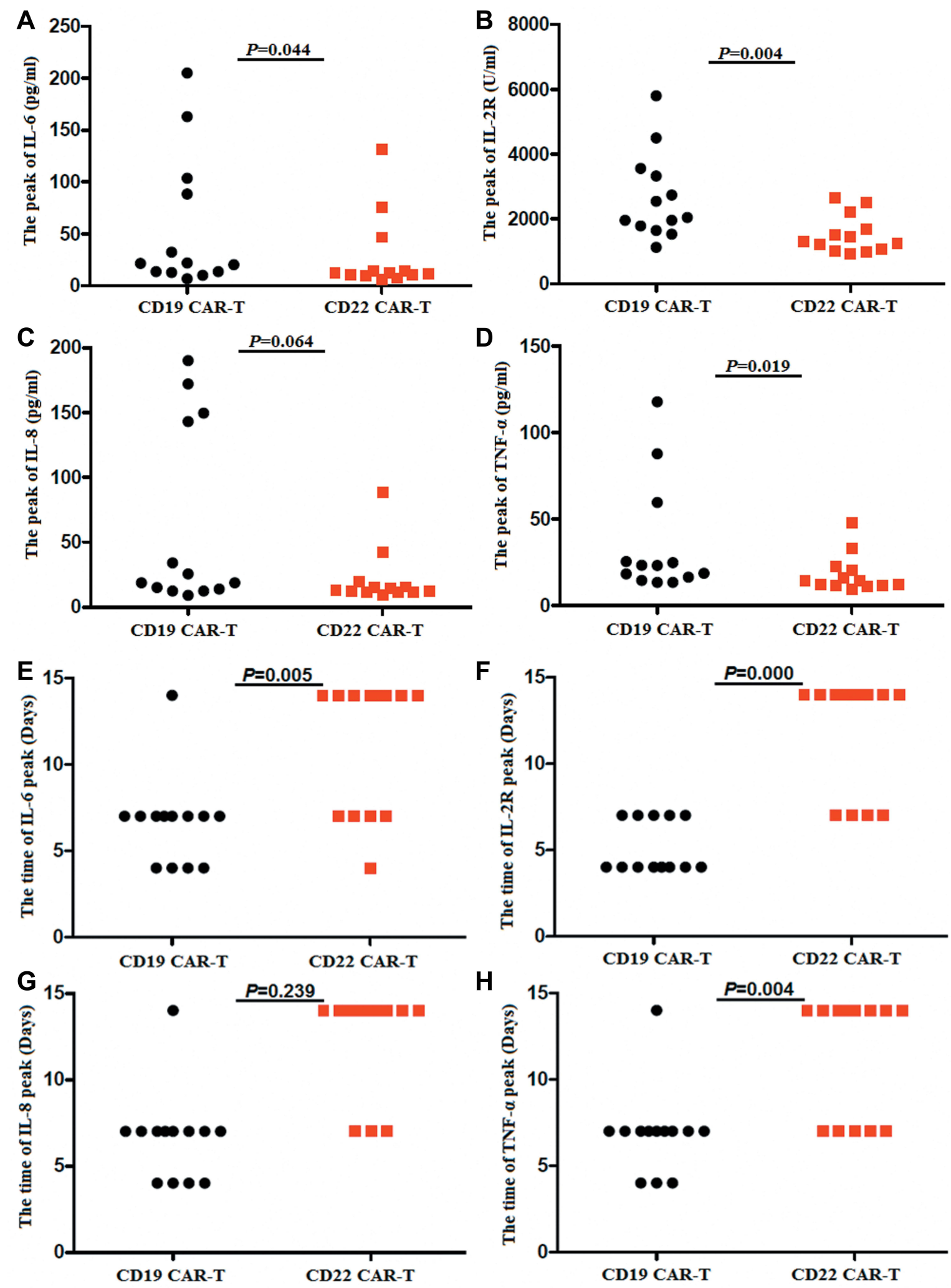

Figure 7 Different of the peaks and peak times of the serum cytokines. (A-D). The peaks of IL-6, IL-2R and TNF- $\alpha$ were higher in anti-CDI9-CAR T cell therapy than that of in anti-CD22-CAR T cell therapy. (E-H). The time of the mean peaks of IL-6, IL-2R and TNF- $\alpha$ in anti-CD22-CAR T cell therapy were later than that of the time in antiCDI9-CAR T cell therapy. 
anti-CD22-CAR $T$ cell therapy is highly effective in $R / R$ DLBCL patients who failed in anti-CD19-CAR T cell therapy before. The anti-CD22-CAR $\mathrm{T}$ cell salvage therapy is more effective in R/R DLBCL patients than that in R/R B-ALL patients. Further clinical observation is needed in the future.

How to maintain remission status is a challenge after CAR-T cell therapy in R/R DLBCL and B-ALL, especially in patients who could not receive bridging hematopoietic stem cell transplantation. ${ }^{6}$ Some studies ${ }^{21,23,33-37}$ suggested that CAR-T cell therapy targeting both CD19 and CD22 might reduce tumor escape and might achieve more lasting remission than targeting a single CD19 or CD22antigen. But not all R/R DLBCL and R/R B-ALL patients could receive a two-target of anti-CD19-CAR and anti-CD22-CAR T cell therapy. Our results could suggest that R/R DLBCL patients rather than R/R B-ALL patients might benefit from the anti-CD22-CAR $T$ cell salvage therapy. Of course, a larger number of patients need to be enrolled in order to confirm these conclusions.

\section{Conclusion}

We found that the anti-CD22-CAR T cell salvage therapy is highly effective in $R / R$ DLBCL patients than in $R / R$ B-ALL patients who failed in anti-CD19-CAR T cell therapy before. The anti-CD22-CAR $\mathrm{T}$ cell therapy showed effective anti-tumor activity as a salvage therapy with controllable toxicity. We need to expand the number of $\mathrm{R} / \mathrm{R}$ DLBCL or B-ALL patients and continue to observe.

\section{Abbreviations}

ALL, acute lymphoid leukemia; AEs, adverse events.AntiCD22-CAR, anti-CD22 chimeric antigen receptor; CAR, chimeric antigen receptor; CRS, cytokine release syndrome; $\mathrm{CR}$, complete response; Cri, $\mathrm{CR}$ with incomplete count recovery; DLBCL, diffuse large B-cell lymphoma; FCM, flow cytometry; HSCT, hematopoietic stem cell transplant; ICANS, Immune effector cell associated neurotoxic syndrome; IL-6, the interleukin-6; NHL, NonHodgkin's lymphoma; NR, no remission; OS, the overall survival; ORR, overall response rate; PD, progression of disease; PR, partial remission; qPCR, quantitative polymerase chain reaction; $\mathrm{R} / \mathrm{R}$, relapsed/refractory; $\mathrm{SD}$, stable disease; TNF- $\alpha$, tumor necrosis factor- $\alpha$.

\section{Data Sharing Statement}

The datasets used and/or analyzed during this study are available from the corresponding authors on reasonable request.

\section{Declarations}

This study was approved by the Medical Ethics Committee of the Department of Hematology, Tianjin First Center Hospital (Tianjin, China). (Approved No. of ethic committee: $2018 \mathrm{~N} 105 \mathrm{KY}$ and $2015002 \mathrm{X}$ ), and informed consent was obtained from the participants. All the data and material have been performed in accordance with the Declaration of Helsinki and conformed to relevant aspects of the ARRIVE guidelines.

The Clinical trial in our study was registered at http:// www.chictr.org.cn/index.aspx as ChiCTR-ONN-16009862 and ChiCTR1800019298.

\section{Consent for Publication}

All the patients provided signed consent before enrollment in the clinical trial and agreed to the use of his specimens and data for our study.

All authors contributed to data analysis, drafting or revising the article, have agreed on the journal to which the article will be submitted, gave final approval of the version to be published, and agree to be accountable for all aspects of the work.

\section{Acknowledgments}

We thank all our patients for their participation in our clinical trials.

\section{Funding}

There is no funding to report.

\section{Disclosure}

The authors declare that they have no conflict of interests.

\section{References}

1. Zeng C, Cheng J, Li T, et al. Efficacy and toxicity for CD22/CD19 chimeric antigen receptor T-cell therapy in patients with relapsed/refractory aggressive B-cell lymphoma involving the gastrointestinal tract. Cytotherapy. 2020;22(3):166-171. doi:10.1016/j.jcyt.2020.01.008

2. Wei J, Zhu X, Mao X, et al. Severe early hepatitis B reactivation in a patient receiving anti-CD19 and anti-CD22 CAR $\mathrm{T}$ cells for the treatment of diffuse large B-cell lymphoma. J Immunother Cancer. 2019;7:315. doi:10.1186/s40425-019-0790-y

3. Wang H, Kaur G, Sankin AI, et al. Immune checkpoint blockade and CAR-T cell therapy in hematologic malignancies. J Hematol Oncol. 2019;12:59. doi:10.1186/s13045-019-0746-1

4. Locke FL, Ghobadi A, Jacobson CA, et al. Long-term safety and activity of axicabtagene ciloleucel in refractory large B-cell lymphoma (ZUMA-1): a single-arm, multicentre, Phase 1-2 trial. Lancet Oncol. 2019;20:31-42. doi:10.1016/S1470-2045(18)30864-7

5. Bishop MR, Maziarz RT, Waller EK, et al. Tisagenlecleucel in relapsed/refractory diffuse large B-cell lymphoma patients without measurable disease at infusion. Blood Adv. 2019;3(14):2230-2236. doi:10.1182/bloodadvances.2019000151 
6. Pan J, Niu Q, Deng B, et al. CD22 CAR T-cell therapy in refractory or relapsed B acute lymphoblastic leukemia. Leukemia. 2019;33:2854-2866. doi:10.1038/s41375-019-0488-7

7. Kenderian SS, Porter DL, Gill S. Chimeric antigen receptor T cells and hematopoietic cell transplantation: how not to put the CART before the horse. Biol Blood Marrow Transpl. 2017;23(2):235-246. doi:10.1016/j.bbmt.2016.09.002

8. Guedan S, Delgado J. Immobilizing a moving target: CAR T cells hit CD22. Clin Cancer Res. 2019;25(17):5188-5190. doi:10.1158/10780432.CCR-19-1649

9. Shah NN, Highfill SL, Shalabi H, et al. CD4/CD8 T-Cell Selection Affects Chimeric Antigen Receptor (CAR) T-Cell Potency and Toxicity: updated Results From a Phase I Anti-CD22 CAR T-Cell Trial. J Clin Oncol. 2020;JCO1903279.

10. Olejniczak SH, Stewart CC, Donohue K, Czuczman MS. A quantitative exploration of surface antigen expression in common B-cell malignancies using flow cytometry. Immunol Invest. 2006;35 (1):93-114. doi:10.1080/08820130500496878

11. Clark EA, Giltiay NV. CD22: a Regulator of Innate and Adaptive B Cell Responses and Autoimmunity. Front Immunol. 2018;9:2235. doi:10.3389/fimmu.2018.02235

12. Fry TJ, Shah NN, Orentas RJ, et al. CD22-targeted CAR T cells induce remission in B-ALL that is naive or resistant to CD19-targeted CAR immunotherapy. Nat Med. 2018;24(1):20-28. doi:10.1038/ nm. 4441

13. Cheson BD, Fisher RI, Barrington SF, et al. Recommendations for initial evaluation, staging, and response assessment of Hodgkin and non-Hodgkin lymphoma: the Lugano classification. J Clin Oncol. 2014;32(27):3059-3068. doi:10.1200/JCO.2013.54.8800

14. Jia W, Qi D, Yan-yu J, et al. CAR-T19 combined with reduced-dose PD-1 blockade therapy:A case report of refractory follicular lymphoma. Oncol Lett. 2019;18:4415-4420. doi:10.3892/ ol.2019.10783

15. Lee DW, Gardner R, Porter DL, et al. Current concepts in the diagnosis and management of cytokine release syndrome. Blood. 2014;124(2):188-195. doi:10.1182/blood-2014-05-552729.

16. Lee DW, Santomasso BD, Locke FL, et al. ASTCT Consensus Grading for Cytokine Release Syndrome and Neurologic Toxicity Associated with Immune Effector Cells. Biol Blood Marrow Tr. 2019;25(4):625-638. doi:10.1016/j.bbmt.2018.12.758.

17. Zhang X, Li J, Lu P. Advances in the development of chimeric antigen receptor-T-cell therapy in B-cell acute lymphoblastic leukemia. Chin Med J. 2020;133(4):474-482. doi:10.1097/ CM9.0000000000000638

18. Jacobson CA, Farooq U, Ghobadi A. Axicabtagene ciloleucel, an anti-CD19 chimeric antigen receptor T-cell therapy for relapsed or refractory large B-cell lymphoma: practical implications for the community oncologist. Oncologist. 2020;25(1):e138-e146. doi:10.1634/ theoncologist.2019-0395

19. Yan Z, Li L, Wang W, et al. Clinical efficacy and tumor microenvironment influence in a dose-escalation study of anti-CD19 chimeric antigen receptor T cells in refractory B-cell Non-Hodgkin's lymphoma. Clin Cancer Res. 2019;25(23):6995-7003. doi:10.1158/ 1078-0432.CCR-19-0101

20. Kochenderfer JN, Dudley ME, Kassim SH, et al. Chemotherapyrefractory diffuse large B-cell lymphoma and indolent B-cell malignancies can be effectively treated with autologous $\mathrm{T}$ cells expressing an anti-CD19 chimeric antigen receptor. J Clin Oncol. 2015;33 (6):540-549. doi:10.1200/JCO.2014.56.2025

21. Qin H, Ramakrishna S, Nguyen S, et al. Preclinical Development of Bivalent Chimeric Antigen Receptors Targeting Both CD19 and CD22. Mol Ther Oncolytics. 2018;11:127-137. doi:10.1016/j. omto.2018.10.006
22. Guedan S, Ruella M, June CH. Emerging Cellular Therapies for Cancer. Anпu Rev Immunol. 2019;37:145-171. doi:10.1146/annurevimmunol-042718-041407

23. Dai $\mathrm{H}$, Wu Z, Jia H, et al. Bispecific CAR-T cells targeting both CD19 and CD22 for therapy of adults with relapsed or refractory B cell acute lymphoblastic leukemia. J Hematol Oncol. 2020;13:30. doi:10.1186/s13045-020-00856-8

24. Ereño-Orbea J, Sicard T, Cui H, et al. Molecular basis of human CD22 function and therapeutic targeting. Nat Commun. 2017;8:764. doi:10.1038/s41467-017-00836-6

25. Macauley MS, Crocker PR, Paulson JC. Siglec regulation of immune cell function in disease. Nat Rev Immunol. 2014;14(10):653-666. doi:10.1038/nri3737

26. Sullivan-Chang L, O'Donnell RT, Tuscano JM. Targeting CD22 in B-cell malignancies: current status and clinical outlook. BioDrugs. 2013;27(4):293-304. doi:10.1007/s40259-013-0016-7

27. Leonard JP, Link BK. Immunotherapy of non-Hodgkin's lymphoma with hLL2 (epratuzumab, an anti-CD22 monoclonal antibody) and Hu1D10 (apolizumab). Semin Oncol. 2002;29(1):81-86. doi:10.1053/ sonc.2002.30149

28. Leonard JP, Goldenberg DM. Preclinical and clinical evaluation of epratuzumab (anti-CD22 IgG) in B-cell malignancies. Oncogene. 2007;26(25):3704-3713. doi:10.1038/sj.onc. 1210370

29. Ogura M, Hatake K, Ando K, et al. Phase I study of anti-CD22 immunoconjugate inotuzumab ozogamicin plus rituximab in relapsed/refractory B-cell non-Hodgkin lymphoma. Cancer Sci. 2012;103(5):933-938. doi:10.1111/j.1349-7006.2012.02241.x

30. Fayad L, Offner F, Smith MR, et al. Safety and clinical activity of a combination therapy comprising two antibody-based targeting agents for the treatment of non-Hodgkin lymphoma: results of a phase I/II study evaluating the immunoconjugate inotuzumab ozogamicin with rituximab. J Clin Oncol. 2013;31(5):573-583. doi:10.1200/JCO.2012.42.7211

31. Davila ML, Riviere I, Wang X, et al. Efficacy and toxicity management of 19-28z CAR T cell therapy in B cell acute lymphoblastic leukemia. Sci Transl Med. 2014;6(224):224ra25. doi:10.1126/ scitranslmed.3008226

32. Lee DW, Kochenderfer JN, Stetler-Stevenson M, et al. T cells expressing CD19 chimeric antigen receptors for acute lymphoblastic leukaemia in children and young adults: a phase 1 dose-escalation trial. Lancet. 2015;385(9967):517-528. doi:10.1016/S0140-6736(14) 61403-3

33. Hamieh M, Dobrin A, Cabriolu A, et al. CAR T cell trogocytosis and cooperative killing regulate tumour antigen escape. Nature. 2019;568 (7750):112-116. doi:10.1038/s41586-019-1054-1

34. Zah E, Lin MY, Silva-Benedict A, et al. T cells expressing CD19/ CD20 bispecific chimeric antigen receptors prevent antigen escape by malignant B cells. Cancer Immunol Res. 2016;4(6):498-508. doi:10.1158/2326-6066.CIR-15-0231

35. Dai H, Zhang W, Li X, et al. Tolerance and efficacy of autologous or donor-derived $\mathrm{T}$ cells expressing CD19 chimeric antigen receptors in adult B-ALL with extramedullary leukemia. Oncoimmunology. 2015;4(11):e1027469. doi:10.1080/2162402X.2015.1027469

36. Maude SL, Frey N, Shaw PA, et al. Chimeric antigen receptor T cells for sustained remissions in leukemia. $N$ Engl J Med. 2014;371 (16):1507-1517. doi:10.1056/NEJMoa1407222

37. Rosenthal J, Naqvi AS, Luo M, et al. Heterogeneity of surface CD19 and CD22 expression in B lymphoBlastic leukemia. American Journal of Hematology. 2018;93(11):E352-E355. doi:10.1002/ ajh. 25235 


\section{Publish your work in this journal}

OncoTargets and Therapy is an international, peer-reviewed, open access journal focusing on the pathological basis of all cancers, potential targets for therapy and treatment protocols employed to improve the management of cancer patients. The journal also focuses on the impact of management programs and new therapeutic agents and protocols on patient perspectives such as quality of life, adherence and satisfaction. The manuscript management system is completely online and includes a very quick and fair peer-review system, which is all easy to use. Visit http://www.dovepress.com/ testimonials.php to read real quotes from published authors.

Submit your manuscript here: https://www.dovepress.com/oncotargets-and-therapy-journal 